\title{
Family Therapy with Muslims
}

Manijeh Daneshpour

Routledge, 2016, 205 pp., \$58.99 (AU Paperback), ISBN: 9781138947979

doi:10.1017/edp.2017.4

In consideration of the current social and political climate surrounding Islam and Muslim communities, a guide that assists mental health professionals who work with Muslims in a family therapy setting is timely and a first of its kind. Manijeh Daneshpour, a family therapist with decades of clinical and academic experience, offers practical guidance in the application of family therapy models within the context of the spiritual, social, and political history of Muslim communities.

The author divides the book into two sections, the first of which includes four chapters which aim to provide the reader with a detailed understanding of Islamic beliefs, family values, and the impact of political and social issues in Muslim communities. Chapter one outlines Muslim beliefs and provides readers with an insight into the theology and practices of the Islamic faith. The second chapter covers the differences and similarities between the family values of 23 Muslim countries. The method of defining Muslim family values according to the country of origin appears overly simplistic and possibly stereotypical. Nonetheless, the author encourages the reader to consider the diversity of Muslim families and the 'inter-ethnic' and 'intra-ethnic' differences within various Islamic cultural groups. The third and fourth chapters describe the impact of colonialism and gender issues on Muslim family values and practices and the implications when working with Muslim families in a clinical setting. Whilst outlining the issues surrounding gender and power inequalities within Muslim families, the author promotes an understanding of individual differences amongst Muslim women and highlights the dangers of relying on common stereotypes.

The second section comprises eight chapters, which are devoted to the various family therapy models and their clinical application with Muslim families. The utility of this well-referenced book is enhanced by the case studies and templates that are provided throughout this section which serve to give greater insight to some common case presentations.

Educational and Developmental Psychologists working with Muslim families will appreciate the informative and practical aspects of this book. Working with clients from different cultural and religious backgrounds can often be challenging and cultural information which is credible and clinically relevant may be difficult to source. The book does not assume an expert level of skill or training in family therapy approaches and introductory information about the various family therapy models are outlined.

A guide for therapy with Muslims may be viewed as further adding to the stereotyping of Muslims and reinforcing the idea of a "one size fits all" approach. However, the author provides clinicians with practical methods of applying various family therapy models to Muslim families in a culturally sensitive manner, encouraging compassion and understanding to ensure treatment efficacy. This is especially relevant considering many Muslims living in the West are feeling isolated and marginalised 
due to the current political climate and this book may serve to guide clinicians in working sensitively with Muslim families and achieving desired outcomes.

Overall, 'Family Therapy with Muslims' is a balanced and useful guide for mental health professionals who work with Muslim individuals and families.

Mrs Sulaima Samman

Educational and Developmental Psychologist, Flying High Child Psychology,

Sydney, Australia 